\title{
Metodologías activas para la enseñanza plurilingüe con estudiantes universitarios
}

María José Carrasco-Macías UnIVERSIDAD DE HUELVA

Huelva, España mjcarra@uhu.es

María del Pilar García-Rodríguez Universidad de HUELVA Huelva, España

\section{Resumen}

mpgarcia@dedu.uhu.es

La investigación realizada tiene como objetivo profundizar en la aplicación del enfoque AICLE/CLIL (Aprendizaje Integrado de Contenidos y Lenguas Extranjeras/Content and Language Integrated Learning) combinado con metodologías activas en la impartición de las asignaturas School Organization and Teaching, Curriculum Development y Teacher Practicum I y II. Hemos realizado una investigación cualitativa con estudio de caso en un grupo del grado de educación primaria de la Universidad de Huelva (España). Este fue seleccionado intencionalmente por ser la primera promoción plurilingüe. Los resultados obtenidos muestran valoraciones positivas en más del $90 \%$ de los participantes y se han identificado mejoras necesarias para el éxito de este tipo de programas.

\section{Palabras claves}

AICLE (Aprendizaje Integrado de Contenidos y Lenguas Extranjeras); multilingüismo; educación superior

\section{Transferencia a la práctica}

Actualmente, el desarrollo de la competencia lingüística en varios idiomas es una preocupación del sistema educativo europeo en todas sus etapas. El fomento de diferentes programas de plurilingüismo por las administraciones educativas es uno de los objetivos primordiales de los gobiernos de la Unión Europea. Nuestra investigación contribuye a la mejora de prácticas docentes para la educación superior en el marco del multilingüismo, ya que analizamos las metodologías utilizadas para el desarrollo de la competencia lingüística en segunda lengua e intentamos que este análisis pueda ofrecer nuevas propuestas metodológicas para atender a la diversidad lingüística y alcanzar el objetivo marcado, entre otros organismos, por el Consejo de Europa.

Para citar este artículo / To cite this article / Pour citer cet article / Para citar este artigo

Gómez-Hurtado, I.; Carrasco-Macías, M. J. \& García-Rodríguez, M. P. (2016) Metodologías activas para la enseñanza plurilingüe con estudiantes universitarios. magis, Revista Internacional de Investigación en Educación, 9(18), 173-192. http://dx.doi.org/10.11144/Javeriana.m9-18.maep 


\section{Keywords}

CLIL / Content and Language

Integrated Learning; multilingualism;

higher education

\section{Mots clés}

AICLE (apprentissage intégré de contenus et langes étrangers); multilingues; éducation supérieure

\section{Abstract}

The research aims to deepen the application of the CLIL / Content and Language Integrated Learning (CLIL) approach combined with active methodologies in the teaching of School Organization and Teaching, Curriculum Development and Teacher Practicum I and II. We have carried out a qualitative research based on a case study of a group of the primary education degree of the University of Huelva (Spain). This was intentionally selected as the first multilingual promotion. Results show positive evaluations in more than $90 \%$ of the participants and improvements have been identified for the success of this type of programs.

\section{Transfer to practice}

At present, the development of linguistic competence in several languages is a concern of the European educational system. The promotion of different programs of multilingualism by the educational administrations is one of the primary objectives of the governments of the European Union. Our research contributes to the improvement of teaching practices for higher education in the context of multilingualism. We analyze the methodologies used for the development of the second language linguistic competence. We aim that this analysis can offer new methodological proposals to attend the linguistic diversity and to achieve the objective marked by the Council of Europe.

\section{Palavras chave}

AICLE (Aprendizagem Integrada de Conteúdos e Línguas Estrangeiras); multilingüismo; educação superior

\section{Résumé}

La recherche qu'on a faite a en tant qu'objectif approfondir dans l'application de la perspective AICLE/CLIL (apprentissage intégré de contenus et langes étrangers/ Content and Language Integrated Learning) articulé avec les méthodologies active dans l'exercice de cours School Organization and Teaching, Curriculum Development y Teacher Practicum I y II. On a réalisé une recherche qualitative avec une étude de cas dans un groupe du dégrée d'éducation primaire de l'Université de Huelva (Espagne) Ce groupe a été choisi pour être la première promotion plurilingue. Les résultats obtenus montrent les considérations positives dans plus du $90 \%$ des participants et on a identifié les améliorations nécessaires pour le succès de ce type de programmes.

\section{Transfert à la pratique}

Aujourd'hui, le développement de la compétence linguistique dans plusieurs langues est une préoccupation du système éducatif européen dans tous les moments. Le phénomène de différents programmes de plurilinguisme de la part des administrations éducatives est une des objectifs principaux des gouvernements de I'Union Européenne. Notre recherche contribue à l'amélioration de pratiques des enseignants pour l'éducation supérieure dans le cadre du multilinguisme, puisqu'on analyse les méthodologies pour prendre soin de la diversité linguistique et parvenir à l'objectif tracé parmi d'autres organismes, pour le Conseil d'Europe.

\section{Transferência à prática}

\section{Resumo}

A pesquisa realizada tem como objetivo aprofundar a aplicação do enfoque AICLE/ CLIL (Aprendizagem Integrada de Conteúdos e Línguas Estrangeiras/Content and Language Integrated Learning) combinado com metodologias ativas no desenvolvimento das matérias School Organization and Teaching, Curriculum Development $e$ Teacher Practicum I e II. Realizamos uma pesquisa qualitativa com estudo de caso em um grupo de educação primária da Universidade de Huelva (Espanha). Referido grupo foi escolhido intencionalmente por ser a primeira promoção plurilíngue. Os resultados obtidos mostram avaliações positivas em mais de $90 \%$ dos participantes e a identificação de melhoras necessárias para o sucesso deste tipo de programas.
Atualmente, o desenvolvimento da competência linguística em vários idiomas é uma preocupação do sistema educativo europeu em todas suas etapas. O fomento de diferentes programas plurilíngues pelas administrações educativas é um dos objetivos primordiais dos governos da União Europeia. Nossa pesquisa contribui na meIhora de práticas docentes para a educação superior no marco do multilinguismo, já que analisamos as metodologias utilizadas para o desenvolvimento da competência linguística em segunda língua e buscamos que esta análise possa oferecer novas propostas metodológicas para atender à diversidade linguística e atingir o objetivo marcado pelo Conselho da Europa, entre outros organismos. 


\section{Introducción}

Según el Eurobarómetro (Comisión Europea, 2006), el término multilingüismo hace referencia tanto a una situación en la que se hablan varias lenguas en una zona geográfica determinada, como a la capacidad de una persona para utilizar varios idiomas. El multilingüismo —en sus dos sentidos - es una característica esencial de Europa. Eso significa que los estudiantes universitarios deben aspirar a tener una lengua materna (o dos, en el caso de las comunidades bilingües), y al menos manejar dos lenguas extranjeras. En esta línea y según Eva Alcón-Soler (2011), la consecuencia del multilingüismo será lograr que los individuos hagan uso de varias lenguas, para conseguir objetivos comunicativos concretos. Así mismo, la meta establecida por el Marco común europeo de referencia para las lenguas: aprendizaje, enseñanza, evaluación (Consejo de Europa, 2002) es dar respuesta a la protección de la diversidad lingüística y cultural de Europa, facilitar la comunicación e interacción entre los europeos por medio de un mejor conocimiento de las lenguas extranjeras, y conseguir una mayor convergencia entre los diferentes estados miembros a la hora de aplicar políticas coordinadas en el campo del aprendizaje y la enseñanza de lenguas (p. 2).

Desde la perspectiva de la propia institución universitaria, "tenemos la necesidad de ofrecer un perfil internacional que facilite la difusión de la investigación, la inserción en el mercado internacional de graduados y la captación de estudiantes extranjeros..." (Alcón-Soler, 2011, p. 120). Por tanto, y siguiendo a esta misma autora, si una universidad se define como multilingüe, su objetivo será formar a los integrantes de la comunidad universitaria para que se conviertan en ciudadanos plurilingües.

Las investigaciones dedicadas a las prácticas de docencia multilingüe, específicamente al uso de la metodología CLIL son cada vez más importantes y frecuentes (Coyle, 2010; Dalton-Puffer, 2011; Dalton-Puffer, Nikula \& Smit, 2010; Marsh, 2008), y presentan una gran variabilidad en su aplicación (Dafouz-Milne \& Llinares-García, 2008); no se puede hablar, por tanto, de una implementación homogénea (Lasagabaster, 2012). De ahí que encontremos programas en los que las materias se imparten en varios idiomas, otros en los que cada materia se desarrolla con programas bilingües (empleando en cada una el idioma que el profesor determine), y otros en los que se combinan todas las opciones. Entendemos bilingüismo, en términos de Agnes Lam (2001), como el fenómeno de competencia y comunicación en dos lenguas (una de las cuales mayoritariamente suele ser el inglés).

La sociedad necesita una educación que contribuya a dar respuesta a las demandas y cambios sociales que se producen en ella. Entre esas necesidades está el fomento de lenguas europeas en los centros educativos. Es fundamental el desarrollo del nivel de idioma hasta convertirlo en una necesidad. Un posible camino es la mejora de las lenguas con clases que se llevan a cabo en varios idiomas (Andersson, Kagwesage \& Rusanganwa, 2013; informe de la Comisión de las Comunidades Europeas, 2003; recomendación de la Comisión Europea de 1998 en la Declaración Mundial sobre la Educación Superior en el Siglo XXl; Consejo de Europa, 2009; UNESCO, 2003). En definitiva, estas declaraciones e informes internacionales instan a las instituciones universitarias a promover cambios en su docencia y en el aprendizaje de idiomas, para apoyar la práctica del plurilingüismo, y destinar fondos a programas de movilidad que supongan el intercambio de docentes y estudiantes, entre otras medidas.
Descripción del artículo | Article description | Description de l'article | Artigo descrição

El presente artículo de investigación recoge el proyecto "Plan Plurilingüe de la Facultad de Educación de la Universidad de Huelva", en el que se presenta una investigación educativa longitudinal de metodología mixta, basada en un cuestionario abierto, entrevistas, observación, diario de la profesora y análisis de documentos. Aplicamos metodologías activas en $1^{\circ}, 2^{\circ}$ y $4^{\circ}$ del grado de educación primaria en las asignaturas de organización de centros educativos, y didáctica y desarrollo curricular, con el enfoque CLIL, dentro del Plan Plurilingüe de la Facultad de Ciencias de la Educación de la Universidad de Huelva. La meta ha sido mejorar los procesos de enseñanza y aprendizaje de las competencias básicas y específicas. 
Partiendo de estos objetivos, empezaron a desarrollarse iniciativas de cambio en el Espacio Europeo de Educación Superior, EEES. De esta forma, muchas universidades de algunos países nórdicos, como Finlandia o Noruega, emprendieron programas de enseñanza bilingüe, bajo el paraguas metodológico CLIL. Universidades de algunos países de Europa Central y el Norte de Europa comenzaron la experiencia con titulaciones de ingeniería y empresariales, sobre todo en niveles de posgrado. Según James A. Coleman (2006), Holanda y Finlandia, seguidos de Alemania, son los países con una mayor oferta de programas en inglés. En muchos de ellos ha surgido cierta controversia ante el temor de perder su lengua nativa en el entorno académico a favor del inglés, hecho que se extiende a España en comunidades con dos lenguas maternas (Cots, Lasagabaster \& Garrett, 2012).

Frente a estos casos, la realidad de muchas comunidades y universidades españolas es la de tener que afrontar un bajo nivel generalizado en una segunda lengua (Rubio-Alcalá \& Hermosín-Mojeda, 2010).

Otros estudios como los de Do Coyle (2004, 2007), Emma Dafouz-Milne y Michele C. Guerrini (2009), Francisco Lorenzo (2002, 2008), Víctor Manuel Pavón-Vázquez (2009), Víctor Manuel Pavón-Vázquez y Fernando Rubio-Alcalá (2010), Fernando David Rubio-Alcalá y Manuel Jesús Hermosín-Mojeda (2010), Isabelle Toledo, Fernando David Rubio-Alcalá y Manuel Jesús Hermosín-Mojeda (2012), Robert Wilkinson (2004), entre otros, muestran diferentes experiencias de la implantación de la metodología CLIL en la educación superior, dada la importancia adquirida de la enseñanza de la segunda lengua y de los continuos planes de fomento de plurilingüismo que se están desarrollando en los diferentes puntos de la geografía española (Junta de Andalucía, 2013), comunidad de Castilla-La Mancha (Suárez-Castiñeira, 2006), País Vasco (Goicoechea-Tabar, Ballarín-Castán \& Fontal-Reglero, 2007). Estas experiencias de currículos integrados español-inglés se realizan desde la segunda mitad de los años 90 en escuelas seleccionadas de toda España (descrito en Hoyos-Pérez, 2011).

En España, también se han generado en los últimos años programas de estudios bilingües en inglés, sobre todo por parte de universidades privadas, que ven en ellos un incentivo para aumentar la matriculación de alumnos. Según Emma Dafouz-Milne y Begoña Núñez-Perucha (2009), más de treinta instituciones educativas están ofreciendo hoy programas bilingües en titulaciones como empresariales, turismo, derecho internacional, ingeniería, telecomunicaciones, farmacia e, incluso, más recientemente humanidades.

Actualmente, las universidades andaluzas están desarrollando el proyecto de excelencia Análisis y Garantía de Calidad de la Enseñanza Plurilingüe en la Educación Superior en Andalucía, para contribuir a la mejora de la calidad de la educación superior plurilingüe en Andalucía. Este proyecto conecta las diferentes experiencias que se están desarrollando en las universidades andaluzas en los grados adaptados al Espacio Europeo de Educación Superior y con otros niveles preuniversitarios que surgen a partir del Plan de Fomento del Plurilingüismo de la Junta de Andalucía.

Unido a la importancia de los idiomas, otro objetivo estratégico es el de mejorar la calidad y la eficacia de la educación y la formación; algunas de las acciones necesarias son las de garantizar “...una docencia de alta calidad, ofrecer una formación inicial del profesorado adecuada, así como un desarrollo profesional continuo de profesores y formadores y hacer de la docencia una opción atractiva de carrera" (Consejo de Europa, 2009).

Esto significa un cambio metodológico en profundidad, que ha de implementarse en las aulas universitarias, como consecuencia del cambio en las políticas europeas, lo que supone además, un cambio en la cultura del aula universitaria. Prueba de ello son los trabajos desarrollados por John Biggs y Catherine Tang (2003), Luis Carlos Contreras-González, José María Rodríguez-López y Francisco José Morales-Gil (2005), Mario de Miguel-Díaz (2006), Ana GarcíaVarcárcel Muñoz-Repiso (2001), Pere Ponsa, Beatriz Amante, José Antonio Román, Sonia Oliver, Marta Díaz y Josep Vives-Gràcia (2009), Joan Rué (2007), Marita Sánchez-Moreno (2007), María Isabel Ubieto-Artur, María Domingo del Valle, Francisco Javier García-Marco \& Antonio Paulo Ubieto-Artur (2008), Miguel Ángel Zabalza-Beraza (2002), Miguel Ángel Zabalza-Beraza y María Ainoha Zabalza-Cerdeiriña (2010), entre otros muchos. Todos ellos muestran que la docencia en la Universidad necesita este cambio hacia metodologías de enseñanza-aprendizaje activas, que permitan el desarrollo de los contenidos y competencias, y su aprendizaje por parte del alumnado. Este tipo de metodologías persigue centrar la enseñanza en los aprendizajes, lograr el aprendizaje autónomo en el alumno, partiendo de sus intereses, la focalización en los resultados - entendiendo estos como adquisición de competencias generales y específicas-, la promoción del trabajo cooperativo, la definición de actividades de enseñanza-aprendizaje, la evaluación conceptualizada como mejora en el proceso, y la importancia de las tecnologías de la información y la comunicación, TIC, en el proceso (Fernández-March, 2006).

En nuestro trabajo, estudiamos en profundidad la aplicación de ambas tendencias: enfoque CLIL y metodologías activas. Entendemos, al igual que autores como María Elvira Barrios-Espinosa (2012), que usar el 
enfoque CLIL supone la adhesión a metodologías activas (en el "aprender haciendo", en la formación en competencias...) y que implica el aprendizaje cooperativo y colaborativo, como el trabajo por proyectos, el enfoque por tareas o la resolución de problemas en grupo.

En muchos de los trabajos mencionados y en otras investigaciones específicas sobre la aplicación del enfoque CLIL (Casal \& Moore, 2009; HoyosPérez, 2011; Lasagabaster 2007), se destacan las ventajas del empleo de este modelo, sus necesidades y dificultades. Entre las ventajas se describen:

- El enfoque en sí mismo, ya que nos lleva a emplear estrategias metodológicas que fomentan la interacción y el uso de la segunda lengua, lo cual es una clara ventaja a la hora de asimilar ese idioma.

- El alumnado suele mejorar su actitud hacia la lengua y hacia su propio aprendizaje.

- Ello hace que en muchos casos desaparezcan la "inhibición, sensación de inferioridad o de bajo nivel" gracias al aumento del uso de la lengua.

- Este aumento, en los estudios de Christiane Dalton-Puffer (2005), está relacionado con la mejora de las habilidades comunicativas y la confianza en el desarrollo de sus capacidades.

Entre las dificultades o mejoras:

- Se necesita una mayor formación del profesorado para que mejoren sus niveles del idioma que se vaya a emplear (en estas experiencias son fundamentalmente el inglés).

- No siempre estos programas consiguen una mejora en el nivel idiomático del alumnado. Así se afirma por ejemplo, en estudios como los de Víctor Manuel Pavón-Vázquez (2009) o Carmen Pérez-Vidal y Nancy Campanale-Grilloni (2005), cuando se trata de experiencias curriculares aisladas y no integradas.

- Se necesitan más recursos, sobre todo humanos que completen y acompañen los procesos; y temporales, para que se puedan desarrollar estas colaboraciones.

Como describimos más adelante, en nuestra experiencia se dan muchas de estas ventajas e inconvenientes.

Los principios metodológicos que van a regir nuestra programación de las materias School Organization and Teaching, Curriculum Development y Teacher Practicum I y II, combinados con el AICLE son:

- Una enseñanza centrada en el alumnado. Ello supone el desarroIlo de clases en las que la cooperación entre el alumnado y entre este y el profesorado se considera básica.

- Una enseñanza flexible y facilitadora, que trata de adaptarse a los distintos estilos de aprendizaje.

- Aprendizajes más autónomos y lógicamente más interactivos. Como se detallará más adelante, los alumnos trabajarán con distintos formatos de agrupamientos.

- Utilización de gran variedad de recursos y materiales, incluidas las TIC.

- Dado que trabajamos competencias, nos enfocaremos en la realización de tareas en las que el uso de la lengua extranjera es una prioridad y un valor. 


\section{Metodología}

Esta investigación surge de una doble preocupación docente: la mejora de los procesos innovadores de enseñanza-aprendizaje propiamente dichos (en el uso de metodologías activas), y el desarrollo de las enseñanzas plurilingües en el aula universitaria.

Nos encuadramos en un enfoque cualitativo para centrarnos en la experiencia de los estudiantes y de una profesora con docencia en lengua inglesa (Coyle, 2013). Nos posicionamos en este paradigma porque los fenómenos educativos son muy complejos y, como indican William Wiersma y Stephen G. Jurs (2000), han de abordarse integralmente; como investigadores sobre nuestra docencia, debemos operar en un entorno natural, estar abiertos y ser flexibles en la evolución investigadora; necesitamos las percepciones de los que están siendo estudiados para comprender el significado del fenómeno educativo, olvidarnos de hipótesis a priori, en favor de unas buenas conclusiones, para adaptarnos al proceso y ser flexibles para intentar llegar a lo más profundo de los informantes (Medina-Moya, 2014).

Concretamente, hemos realizado un estudio de caso etnográfico (Álvarez-Gayou Jurgenson, 2003), ya que nos permite llevar a cabo la observación sobre el terreno, profundizar en situaciones y campos particulares y conseguir así la posibilidad de obtener un conocimiento exhaustivo y cualitativo de fenómenos, hechos y problemas (Donmoyer \& Galloway, 2010; Elliott \& Lukeš, 2008; Johnson \& Christensen, 2004) y para ello, definimos interrogantes que nos aportasen un conocimiento profundo de nuestra docencia, con base en los trabajos de Robert E. Stake (2010) y de Robert K. Yin (2014).

La experiencia objeto de estudio, identificación

y selección del estudio de caso

Se ha hecho el seguimiento a un grupo de 65 alumnos (grupo T3; en esta promoción hubo 4 grupos más que no participaron de la experiencia). Formaban parte del Programa Plurilingüe que se ofertó para toda Andalucía por medio del Distrito Único Andaluz (DUA), para el grado de educación primaria de la Facultad de Ciencias de la Educación, acogidos al Plan de Plurilingüismo de la Universidad de Huelva (UHU).

Este alumnado ha sido la primera promoción de este programa. Comenzaron un grupo de 50 (de acceso directo por DUA) con una alta motivación y con niveles entre un A2 y un B1 en inglés; más 15 alumnos/as que fueron incorporados por incompatibilidades horarias sin nivel certificado en otro idioma, y un grupo variable a lo largo de los años, de estudiantes Erasmus (EuRopean Community Action Scheme for the Mobility of University Students o Plan de Acción de la Comunidad Europea para la Movilidad de Estudiantes Universitarios)' ${ }^{1}$, procedentes de Turquía, Europa del Este y Francia.

Durante la carrera, el grupo ha recibido docencia en inglés el primer curso de grado de la titulación de educación primaria, y francés e inglés para cursos posteriores. Este programa también abarcaba otras titulaciones:

1 El programa Erasmus entra en vigor en 1987 con la finalidad principal de impulsar la movilidad académica. Los objetivos principales se focalizan en conseguir un incremento del número de estudiantes de universidad, de forma que se vaya construyendo un personal con experiencia directa en la vida económica y social de otros Estados miembros. Además, promueve la cooperación entre universidades, al movilizar el potencial del profesorado y el alumnado. En definitiva, persigue la consolidación de una Europa de los ciudadanos mediante el establecimiento de relaciones, en este caso, académicas (Belvis, Pineda \& Moreno, 2007). 
en el grado de educación infantil se han impartido clases en inglés e italiano y para el grado de psicología, también inglés.

Una vez seleccionado el grupo, nos centramos en la experiencia bilingüe en inglés. Esta ha consistido en la impartición de las materias School Organization and Teaching, Didactic and Curriculum Development, Teacher Practicum I y Teacher Practicum II, con metodologías activas y enfoque CLIL. Este acrónimo hace referencia a las situaciones en las que las materias o parte de ellas se enseñan en una lengua extranjera con un objetivo doble: el aprendizaje de contenidos y el aprendizaje simultáneo de una lengua extranjera (Marsh, 1994). La clave del binomio metodologías activas y CLIL —en términos de María Luz Suárez-Castiñeira (2005) - está en que este enfatiza la "resolución de problemas" y "saber hacer cosas" (ambos elementos fundamentales de las metodologías activas y de la enseñanza por competencias), haciendo que los estudiantes de cualquier edad se sientan motivados en un contexto más natural para el desarrollo de las lenguas.

Los contenidos que se han trabajado son competencias básicas de didáctica, organización escolar y desempeño docente en la formación inicial de maestros de primaria, que han sido impartidas por una profesora, pero cuyos materiales y planificación de la materia han sido diseñados por un grupo de profesoras implicadas en el programa desde su comienzo.

Las estrategias didácticas seleccionadas y los materiales que se han diseñado para su implementación han tenido como referentes las tutorías entre iguales, los talleres y los rincones², el trabajo por proyectos, la lección magistral, las lecturas y las exposiciones.

\section{Instrumentos de recogida de la información}

Para la recogida de la información y dado el carácter etnográfico de la investigación, hemos utilizado los siguientes instrumentos:

- Entrevistas semiestructuradas a 20 alumnos del grupo, y una entrevista inicial y otra final a la profesora. Se llevaron a cabo un total de 22 entrevistas.

- Análisis de documentos: se analizaron las guías de las asignaturas (4 guías), las actividades (más de 50 actividades entre todas las materias), las hojas de seguimiento del alumnado (16 hojas grupales), las interacciones en Facebook de las asignaturas (durante 4 meses), la plataforma Moodle (más de 60 documentos subidos), etc.

- Registros observacionales: la observación participante con una hoja de registro diaria que especificaba la descripción de la situación en la clase, el tipo de actividad, las personas implicadas, el papel de la profesora y el alumnado, el lugar y la distribución espacial de los participantes y el clima social durante la actividad. Se incluían las observaciones resaltables y un apartado para resaltar aquellas cuestiones importantes para la investigación. Se analizaron un total de 34 hojas de registro.

- Diario de la profesora: se analizó el diario de observación de la profesora, que esta utilizó como estrategia para la evaluación del alumnado, de su propia planificación didáctica y de su docencia, y nosotros utilizamos como instrumento de recogida de datos en la investigación (1 diario por cada asignatura, un total de 4 diarios).

2 "Podríamos definir los rincones de trabajo como espacios delimitados y concretos, ubicados en las aulas o su entorno más próximo (aprovechamiento de pasillos, corredores ...), donde alumnos y alumnas trabajan de forma simultánea y alrededor de un único proyecto o unidad de programación" (Rodríguez-Torres, 2011, p. 107). 
- Entrevista escrita como instrumento final de la experiencia, contestada por los 65 alumnos. Estaba compuesta por estos interrogantes:

- ¿Crees que los contenidos han sido adecuados?

- ¿Qué cambiarías?

- ¿Qué piensas sobre la metodología seguida por la profesora? Aspectos positivos y negativos.

- ¿Consideras que ha favorecido el aprendizaje?

- ¿Consideras que la profesora maneja y domina los contenidos de la asignatura?

- ¿Qué aspectos positivos y negativos destacarías de ella?

- ¿Crees que el trato de la profesora ha sido el adecuado con los estudiantes? ¿Por qué?

- ¿Qué piensas sobre la impartición de la asignatura en inglés?

- ¿Crees que hubieras aprendido más si hubiera sido en español?

- ¿Consideras que el uso del inglés en el aula mejora las habilidades en este idioma?

- ¿Qué ventajas e inconvenientes identificas en el uso del inglés en esta asignatura?

- ¿Qué nota numérica consideras, en función de lo que has trabajado y estudiado, que debes tener en la asignatura? Justifica tu respuesta.

Objetivos y preguntas clave

El objetivo general que nos proponemos en esta investigación es el de "analizar y evaluar la docencia en inglés impartida por la profesora, concretamente, los métodos, recursos y estrategias didácticas utilizados y las actitudes y el aprendizaje del alumnado en los mismos".

Este objetivo general se concreta en objetivos más precisos y específicos que nos llevarán a la construcción del rompecabezas, que no es otro que nuestro objeto de estudio. Estos objetivos coinciden con las preguntas clave del caso:

- Conocer las actitudes del alumnado y la profesora ante la docencia en inglés.

- Profundizar en la metodología, los recursos y las estrategias didácticas que utiliza la profesora.

- Describir el estilo docente de la profesora en los grupos plurilingües desde la perspectiva del alumnado.

- Describir la influencia del uso del inglés en el aprendizaje desde el punto de vista del alumnado.

\section{El trabajo de campo y análisis de datos}

El trabajo ha sido de carácter longitudinal, para adentrarnos en la realidad del aula durante ocho meses en dos cursos académicos diferentes y hemos seguido teniendo contacto con el grupo en cursos posteriores, al establecer reuniones a lo largo de las prácticas en los dos cursos siguientes.

El proceso de investigación que hemos seguido corresponde al modelo de investigación cualitativa con estudio de casos de Robert K. Yin (2014), que constituye un proceso abierto y flexible.

La primera fase del proceso ha sido la preparatoria. En ella, hemos diseñado el proyecto de investigación y hemos realizado una búsqueda bibliográfica para establecer unos objetivos sólidos basados en la literatura existente y en la realidad del aula que íbamos a investigar. Tras construir 
una fundamentación teórica contundente, comenzamos la segunda fase, el trabajo de campo, a partir de la recogida productiva de datos con los diferentes instrumentos ya expuestos siguiendo los principios para realizar un estudio de caso etnográfico. La recogida de información se realizó de manera intensiva durante las clases, por tratarse de docencia reglada en el aula y despúes de ellas, mediante reuniones, pues se trataba de prácticas profesionales externas.

La accesibilidad al campo ha sido una realidad, ya que impartíamos clase en este grupo y se había establecido una relación profesora-alumno muy estrecha. Una vez recogida toda la información, pasamos a la fase análitica para reducir los datos y analizarlos utilizando un sistema de categorías con base en las preguntas del estudio, buscando hacer descripciones que reflejasen las percepciones de los participantes. Para la elaboración de estas categorías, se siguió un proceso de codificación recurrente, que no es propiamente inductivo ni deductivo, sino un término intermedio entre ambos. También podríamos hablar de codificación o diseño "progresivo", como recoge Froylán Antonio Ceballos-Herrera (2009). En la tabla 1 se presenta el sistema de categorías, los objetivos y las preguntas de investigación para facilitar la comprensión de las categorías existentes.

Tabla 1

Tabla resumen de las categorías, preguntas y objetivos que guían la investigación

\begin{tabular}{|c|c|c|}
\hline \multicolumn{3}{|c|}{ Categorías, preguntas y objetivos que guían la investigación } \\
\hline Categorías & Objetivos & Preguntas \\
\hline Actitudes del alumnado & $\begin{array}{l}\text { - Conocer las actitudes del alumnado y de } \\
\text { la profesora ante la docencia en inglés. }\end{array}$ & $\begin{array}{l}\text { ¿Qué actitudes tiene el alumnado ante el uso } \\
\text { del inglés en el aula? }\end{array}$ \\
\hline Actitudes del profesorado & $\begin{array}{l}\text { - Conocer las actitudes del alumnado y de } \\
\text { la profesora ante la docencia en inglés. }\end{array}$ & $\begin{array}{l}\text { ¿Cuál es la actitud de la profesora ante el uso } \\
\text { del inglés? ¿Promueve la profesora el uso del } \\
\text { inglés en el aula? }\end{array}$ \\
\hline $\begin{array}{l}\text { Metodologías, estrategias } \\
\text { y recursos didácticos } \\
\text { empleados }\end{array}$ & $\begin{array}{l}\text { - Profundizar en la metodología, los } \\
\text { recursos y las estrategias didácticas que } \\
\text { utiliza la profesora. } \\
\text { - Explorar cómo se lleva a cabo la } \\
\text { docencia en inglés en las asignaturas } \\
\text { de organización de centros educativos, } \\
\text { y didáctica y desarrollo curricular en } \\
\text { los grupos plurilingües de educación } \\
\text { primaria. } \\
\text { - Describir el estilo docente de la profesora } \\
\text { en los grupos plurilingües desde las } \\
\text { perspectivas del alumnado. }\end{array}$ & $\begin{array}{l}\text { ¿Qué tipo de metodología utiliza la profesora? } \\
\text { ¿Cómo se describiría? ¿Qué prácticas docentes } \\
\text { utiliza? ¿Cuál es su perfil? ¿Qué estrategias } \\
\text { y recursos didácticos utiliza? ¿Qué tipo de } \\
\text { organización utiliza en el aula? ¿Cuáles son los } \\
\text { rasgos personales y profesionales que presenta } \\
\text { la profesora en sus clases? ¿Qué dificultades } \\
\text { encuentra para realizar sus funciones? ¿Qué tipos } \\
\text { de relaciones personales y profesionales genera } \\
\text { con el alumnado? ¿Qué concepto de la enseñanza } \\
\text { tiene? ¿Qué formación en metodología para el } \\
\text { uso del inglés en el aula tiene el profesorado de } \\
\text { los grupos plurilingües?, etc. }\end{array}$ \\
\hline Aprendizaje del alumnado & $\begin{array}{l}\text { - Explorar, comprender y describir la } \\
\text { influencia del uso del inglés en el } \\
\text { aprendizaje del alumnado. } \\
\text { - Conocer la influencia del uso del inglés } \\
\text { en los rendimientos académicos del } \\
\text { alumnado. } \\
\text { - Conocer cómo aplican en sus prácticas } \\
\text { docentes el uso de estrategias activas } \\
\text { y el uso de la segunda lengua (L2). }\end{array}$ & $\begin{array}{l}\text { ¿Cómo utiliza el inglés en clase? ¿Influye el } \\
\text { inglés en la docencia? ¿Ha influido la docencia } \\
\text { en inglés en el aprendizaje del alumnado? ¿El } \\
\text { uso del inglés afecta los resultados académicos? }\end{array}$ \\
\hline $\begin{array}{l}\text { Propuestas de mejora en } \\
\text { la práctica docente }\end{array}$ & $\begin{array}{l}\text { - Mejorar la práctica docente teniendo } \\
\text { en cuenta a los principales actores del } \\
\text { proceso enseñanza-aprendizaje: la } \\
\text { profesora y el alumnado. }\end{array}$ & $\begin{array}{l}\text { ¿Cómo mejorarían los estudiantes la docencia } \\
\text { impartida por la profesora? ¿Qué variables } \\
\text { deben cambiarse? ¿Cuáles son los principales } \\
\text { aspectos para mejorar la enseñanza en inglés? } \\
\text { ¿Qué prácticas recomiendan los estudiantes } \\
\text { para la mejora de la docencia? }\end{array}$ \\
\hline
\end{tabular}

Fuente: elaboración propia 
En la última fase, la informativa, elaboramos un informe de investigación que en parte recogemos en este artículo.

\section{Resultados}

En la categoría sobre las actitudes del alumnado ante el uso del idioma, encontramos diferentes opiniones. La mayoría del alumnado está en el grupo plurilingüe por su libre elección y considera que el uso del inglés en las dos materias que estamos estudiando y en la experiencia práctica en el aula, es una oportunidad para mejorar el idioma, ser capaz de usarlo con mayor fluidez en sus prácticas externas, crear un ámbito de comunicación constante en ese idioma y "perder la vergüenza y el ridículo a hablar en inglés en público" (Entrevista 5: Estudiante). El $90 \%$ de este alumnado concreta que la enseñanza en inglés es beneficiosa para el desarrollo de las competencias relacionadas con el aprendizaje del idioma. Sin embargo, el 15\% considera el uso del inglés un aspecto positivo pero cree conveniente que para ello el profesorado esté más formado "sabemos que la profesora está intentando mejorar su formación cada día" (Entrevista 30: Estudiante).

En cuanto a las actitudes de la profesora, esta confiesa que en un principio el uso del segundo idioma en el aula la atemorizaba y consideraba que se perdían explicaciones y contenidos de la asignatura: "No me siento segura en las clases; creo que esto está influyendo en la cantidad de ejemplos que podría dar en español y en la explicación de los contenidos, tengo que practicar más las explicaciones en inglés" (Diario profesora: 23 de marzo). No obstante, conforme ha pasado el tiempo, explica que ha buscado estrategias didácticas y recursos que le han permitido obtener más seguridad y que su alumnado tenga un soporte más sólido, también en la segunda lengua, que le permita que no se pierdan los contenidos de la asignatura: "Me siento cada día más a gusto en las clases, parece que voy afrontando mis miedos ante el idioma y el uso de los talleres y rincones en el aula parece que les está gustando y a mí me hace sentirme realizada como docente" (Diario profesora: 15 de diciembre). Además, considera que ha sido una oportunidad para ir mejorando su inglés cada día y una experiencia de crecimiento como docente, porque le ha supuesto la búsqueda de la innovación y el acercamiento a la metodología CLIL y a otras metodologías activas que se han convertido en el vehículo para construir una docencia sólida en inglés: "al principio, estaba siempre muy nerviosa, usar el inglés en clase suponía para mí una preparación excesiva y, aun así, veía que mi nivel no era suficiente, esto me hacía tener mucho estrés... pero con el paso del tiempo, me alegro porque mi nivel de inglés ha mejorado y además la experiencia me ha enriquecido como docente. He aprendido mucho y he tenido que buscarme la vida para que mis alumnos aprendan los mismos contenidos, tengan los mismos ejemplos que si estuviera dando la clase en español" (Entrevista 21: profesora).

Las metodologías, estrategias y recursos didácticos empleados por la profesora se consideran en la mayoría de los casos, activos e innovadores. El alumnado describe la metodología utilizada por la docente haciendo alusión a la gran importancia que esta le daba a la unión entre la teoría y la práctica, en la que el alumno es el centro del proceso de enseñanzaaprendizaje. Un estudiante comenta: "la metodología que utilizaba María se basaba en la unión entre la teoría y la práctica, donde nuestra participación era continua y éramos nosotros los que en cada momento dirigíamos nuestros conocimientos. María era una guía y coordinadora de lo que hacíamos en clase" (Entrevista 12: Estudiante).

Destacan su habilidad para motivar al alumnado con distintas metodologías y estrategias activas: "Yo considero que la metodología ha sido adecuada, siempre he pensado en una clase de María que era imposible que hubiera tantas formas de enseñar un contenido y menos en la universidad. Yo me imaginaba que aquí el profesor era siempre el que debía explicar" (Entrevista 12: Estudiante). Por otro lado, algunos estudiantes consideran que la metodología en algunas ocasiones implicaba demasiado trabajo para el alumno: "Algunas veces pensaba que la metodología de María era muy infantil y que debíamos construir demasiadas cosas nosotros; es verdad que ella nos facilitaba todo lo necesario pero conllevaba mucho trabajo" (Entrevista 8: Estudiante).

Las estrategias utilizadas por la docente, según el alumnado, son estrategias como los talleres en clase, la elaboración de recursos, la interacción con el medio, la tutoría entre iguales, las flashcards, etc., todas ellas para favorecer el aprendizaje no solo de su materia sino también del idioma utilizado (inglés). "No puedo describir una clase de esta profesora porque cada día es diferente, el uso de estrategias es múltiple" (Entrevista 1: Estudiante).

Los recursos didácticos — como talleres, rincones, seminarios de lectura, reproducción de videos, etc. (revisión de la Guía Docente) — son un medio fundamental en las clases de la docente, con el cual trabaja el idioma y es el soporte para el alumnado: "las clases de María están muy trabajadas, elabora gran cantidad de material para que nosotros podamos tener todo el contenido necesario para aprender y además lo hace

3 Nombre ficticio para mantener el criterio de confidencialidad de los datos. 
todo en inglés y español" (Entrevista 5: Estudiante). El 98\% del alumnado, según la entrevista final, opina que la metodología, las estrategias y los recursos didácticos utilizados por la profesora favorecen la comprensión de la materia y apoyan el uso del inglés en la exposición de contenidos, por lo que consideran beneficioso el uso de la metodología AICLE y las metodologías activas para el desarrollo de las asignaturas del Plan Plurilingüe, ya que mejoran la comprensión de los contenidos en ese idioma.

La organización del aula es siempre la misma por la inmovilidad del mobiliario, pero el alumnado describe que para la profesora no es un impedimento, así "utiliza en las clases actividades en grupo, en pareja, individuales, en gran grupo... la organización del espacio no es una barrera para María" (Entrevista 16: Estudiante).

El 95\% de los estudiantes destaca su gran implicación en las clases, su buena relación con el alumnado, su actitud siempre de escucha y su metodología en el aula, considerando que esta última les ha ayudado a mejorar el nivel del idioma, les ha aportado vocabulario específico en la materia en inglés y les ha dado seguridad a la hora de hablar: "Creo que dar estas asignaturas en inglés ha supuesto un gran avance en mi nivel en el idioma, ya que me obligaba a escuchar y hablar y a elaborar las actividades" (Entrevista 8: Estudiante). Otros alumnos consideran que el nivel de la profesora no es suficiente para ayudarles, ya que es inferior al suyo: "Yo tengo un nivel de inglés $\mathrm{C} 1$, así que sí podía seguir bastante bien las explicaciones en inglés. Sin embargo, pienso que mis compañeros escuchaban hablar inglés como el que oye llover, a mí no me ayudaba a mejorar el inglés porque mi nivel era superior" (Entrevista 4: Estudiante).

Todo el alumnado destaca el perfil docente de la profesora, asociado al modelo investigador didáctico que se caracteriza por el desarrollo de un papel del profesor como coordinador de los procesos en el aula que ve al alumno como el principal agente de la misma (García-Prieto, 2014). Resaltan el compromiso con el alumnado, la implicación en sus clases, el esfuerzo y la seguridad en creer que la educación es un agente que produce el cambio y su empatía y actitud de ayuda a todo el alumnado; estos aspectos son claves para la motivación ante el aprendizaje del idioma. "María como profesora es una persona que está dedicada en cuerpo y alma a sus alumnos/as, que dentro del aula te motiva, te hace trabajar duro pero que siempre te ayuda en todo momento. Con ella, podemos llegar a dar el máximo de nuestras posibilidades, incluso más de lo que puedes imaginar en un principio. Es exigente, porque ella misma lo da todo. Fuera del aula, esta profesora siempre está ahí para nosotros/nosotras, siempre está a nuestra disposición para aconsejarnos y ayudarnos con su asignatura, con otras e inclusive con problemas de nuestra vida diaria. Su forma de ser me ha ayudado a mejorar en el inglés y a querer siempre exigirme más" (Entrevista 6: Estudiante).

La formación del profesorado de los grupos plurilingües es puesta en cuestión por el 15\% de los alumnos: "Yo creía que iba a tener a profesorado más formado en idiomas" (Entrevista 7: Estudiante). Sin embargo, en el caso de la docente estudiada el alumnado considera que su nivel de inglés no es suficiente pero su esfuerzo en mejorarlo es diario; este aspecto es fundamental para la motivación de los estudiantes hacia el idioma. El alumnado piensa que la profesora ha compensado su nivel de inglés con el uso de estrategias activas y con la elaboración de todos los recursos en inglés: "María no es nativa pero su nivel de inglés se veía compensado con su dedicación a la docencia. Cada día nos sorprendía con nuevas estrategias y métodos que nos motivaban más y más, siempre intentando sorprendernos manteniendo la incertidumbre hasta el último momento. Lo que más 
me admiraba es que todo estaba en inglés y español y además utilizaba estrategias que se utilizan en las clases de inglés" (Entrevista 11: Estudiante). La profesora nos explica que durante los cuatro años de experiencia ha cursado varios cursos de formación sobre la metodología CLIL, el máster de docencia universitaria en lengua extranjera (inglés) y ha practicado con asistentes lingüísticos las habilidades del idioma. "He intentado compensar mis carencias con el uso de diferentes metodologías didácticas pero sabía que además era necesario que me formara. La Facultad se ha preocupado de facilitarme diferentes recursos como el asistente lingüístico que me ha ayudado a corregir todo el material en inglés y mejorar mis competencias en el idioma y además he tenido la inquietud de cursar el máster en docencia universitaria en inglés que oferta el Servicio de Formación de nuestra Universidad. Además, de forma personal, he recibido clases de inglés para aprender y certificar mi nivel de inglés" (Entrevista Final a la profesora).

Los resultados en las actividades realizadas y en los exámenes han sido muy satisfactorios, pues el 50\% del alumnado utiliza el inglés para realizar estas tareas. El alumnado destaca que la profesora favorecía el uso del inglés y le atribuía parte de la nota de la asignatura.

Por otra parte, en esta experiencia, el aprendizaje de la materia en lengua inglesa no ha influenciado negativamente la adquisición de las competencias. El alumnado destaca que el hecho de recibir las clases en inglés no ha supuesto una pérdida en los contenidos sino una oportunidad para conocer y aprender la terminología de la asignatura en inglés. Uno de ellos comenta: "Para mí, ha sido una experiencia muy rica, ha hecho que conozca vocabulario educativo en inglés y además he conocido muchas cosas de las escuelas en otros países. Me ha encantado ver otras realidades y es lo que me ha animado este año a irme de Erasmus" (Entrevista 9: Estudiante). Esta experiencia no solo ha significado el aprendizaje de vocabulario técnico-profesional, sino también el fomento de movilidad.

Los estudiantes explican que el inglés siempre ha estado presente en clase en las explicaciones, las actividades y los recursos: "María siempre ha utilizado el inglés de alguna forma, su autoexigencia ha hecho que a pesar de sus miedos utilice el inglés en las actividades, explicaciones, etc." (Entrevista 19: Estudiante). La docencia en inglés, según los estudiantes, no ha sido un factor negativo en el rendimiento y aprendizaje de la asignatura. El $85 \%$ de los estudiantes piensa que ha sido más un aspecto positivo al ampliar su conocimiento no solo del idioma sino también del conocimiento de la materia en otros países. "Comienzo a ver que mis estudiantes valoran el uso del inglés, por ejemplo, en la actividad de hoy todos me han comentado que les ha encantado conocer el sistema educativo de Inglaterra y analizarlo en páginas webs de escuelas inglesas que después yo he comentado" (Diario profesora: 21 de marzo).

Un $10 \%$ de los estudiantes piensa que las clases en español serían más ricas, ya que la profesora podría poner más ejemplos y expresar más sus conocimientos.

La última categoría que hemos analizado son las propuestas de mejora en la metodología utilizada por la profesora para impartir sus clases en inglés. En este sentido, la profesora destaca su necesidad de una mayor formación en el propio idioma y también en metodologías que favorezcan el aprendizaje de la lengua, aunque ella puntualiza que no quiere convertirse en una profesora de idioma. El alumnado coincide en que debe mejorar su nivel de inglés pero considera que su metodología, estrategias y recursos favorecen el uso del inglés y son adecuadas para el aprendizaje.

Las principales debilidades y fortalezas para la docente y los estudiantes se concretan en la siguiente tabla: 
Tabla 2

Principales debilidades y fortalezas de la docente y el grupo de estudiantes

por categorías en el proceso de enseñanza/aprendizaje plurilingüe

Debilidades y fortalezas en el proceso de enseñanza/aprendizaje

\begin{tabular}{|c|c|c|c|c|}
\hline \multirow{2}{*}{ Categorías } & \multicolumn{2}{|c|}{ Docente } & \multicolumn{2}{|r|}{ Estudiantes } \\
\hline & Debilidades & Fortalezas & Debilidades & fortalezas \\
\hline Actitudes & $\begin{array}{l}\text { Inseguridad y temor } \\
\text { a la pérdida de } \\
\text { contenidos. }\end{array}$ & $\begin{array}{l}\text { - Mejora de las } \\
\text { competencias en el } \\
\text { segundo idioma. } \\
\text { - Fortalecimiento y } \\
\text { crecimiento como } \\
\text { docente. } \\
\text { - Uso de metodologías } \\
\text { y estrategias activas. } \\
\text { Metodología CLIL. }\end{array}$ & $\begin{array}{l}\text { Más formación } \\
\text { del profesorado. }\end{array}$ & $\begin{array}{l}\text { - Mejora de las competencias } \\
\text { en el aprendizaje del idioma. } \\
\text { - Fluidez en la expresión oral } \\
\text { del segundo idioma. }\end{array}$ \\
\hline $\begin{array}{l}\text { Metodologías, } \\
\text { estrategias } \\
\text { y recursos } \\
\text { didácticos }\end{array}$ & $\begin{array}{l}\text { Gran cantidad de } \\
\text { elaboración de } \\
\text { recursos. } \\
\text { Necesidad de } \\
\text { formación en el } \\
\text { propio idioma } \\
\text { y en estrategias } \\
\text { y metodologías } \\
\text { didácticas para la } \\
\text { enseñanza de un } \\
\text { contenido en otro } \\
\text { idioma. }\end{array}$ & $\begin{array}{l}\text { - Aprendizaje con el } \\
\text { alumnado. } \\
\text { - Desarrollo como } \\
\text { docente. } \\
\text { - Formación en } \\
\text { metodologías activas } \\
\text { y enseñanza AICLE. }\end{array}$ & $\begin{array}{l}\text { - Implican mucho } \\
\text { trabajo para el } \\
\text { alumnado. } \\
\text { - Bajo nivel de } \\
\text { idioma de la } \\
\text { profesora. }\end{array}$ & $\begin{array}{l}\text { - Unión de la teoría con } \\
\text { la práctica. } \\
\text { - El estudiante en el centro } \\
\text { del proceso. } \\
\text { - Habilidad para motivar } \\
\text { al alumnado. } \\
\text { - Favorece el aprendizaje de } \\
\text { la materia y también del } \\
\text { segundo idioma. } \\
\text { - Es beneficioso el uso de } \\
\text { metodologías activas y AICLE. } \\
\text { - Gran implicación en las } \\
\text { clases, buena relación con el } \\
\text { alumnado, actitud siempre de } \\
\text { escucha de la profesora } \\
\text { - Uso del modelo didáctico } \\
\text { investigador. }\end{array}$ \\
\hline $\begin{array}{l}\text { Aprendizaje del } \\
\text { alumnado }\end{array}$ & $\begin{array}{l}\text { Mayor esfuerzo en } \\
\text { el desarrollo de las } \\
\text { tareas de evaluación. }\end{array}$ & $\begin{array}{l}\text { - La docencia en } \\
\text { inglés no ha sido } \\
\text { un factor negativo } \\
\text { en el rendimiento } \\
\text { y aprendizaje de la } \\
\text { asignatura. } \\
\text { - Desarrollo mayor } \\
\text { de competencias en } \\
\text { el segundo idioma, } \\
\text { expresión, análisis y } \\
\text { desarrollo profesional. }\end{array}$ & $\begin{array}{l}\text { - Limitación de la } \\
\text { profesora en la } \\
\text { explicación en } \\
\text { lengua inglesa. } \\
\text { - Mayor esfuerzo } \\
\text { en el proceso. }\end{array}$ & $\begin{array}{l}\text { - Las clases en inglés no han } \\
\text { supuesto una pérdida en los } \\
\text { contenidos. } \\
\text { - El } 50 \% \text { del alumnado utiliza el } \\
\text { inglés para las exposiciones, } \\
\text { actividades y exámenes. } \\
\text { - La docencia en inglés no ha } \\
\text { sido un factor negativo en el } \\
\text { rendimiento y aprendizaje de } \\
\text { la asignatura. } \\
\text { - Aprendizaje de vocabulario } \\
\text { específico de la materia en el } \\
\text { segundo idioma. } \\
\text { - Aprendizaje de los contenidos } \\
\text { de la materia en otros países. }\end{array}$ \\
\hline $\begin{array}{l}\text { Propuestas de } \\
\text { mejora en la } \\
\text { práctica docente }\end{array}$ & $\begin{array}{l}\text { Necesidad de una } \\
\text { mayor formación en } \\
\text { la segunda lengua } \\
\text { y en metodologías } \\
\text { para la enseñanza } \\
\text { en inglés. }\end{array}$ & & $\begin{array}{l}\text { Mejora del nivel } \\
\text { de inglés del } \\
\text { profesorado de los } \\
\text { grupos plurilingües. }\end{array}$ & \\
\hline
\end{tabular}

Fuente: elaboración propia

Finalmente, para superar las debilidades que se han detectado en el proceso se han considerado algunas vías o alternativas como la exigencia de un nivel de idiomas al profesorado participante en los grupos plurilingües, la formación del docente en metodologías activas y AICLE para el dominio de la docencia de los contenidos en una segunda lengua, la selección de los estudiantes para estos grupos por su nivel de idiomas y 
su interés en participar en la experiencia y un mayor número de recursos por parte de la institución para el desarrollo del plan, como asistentes lingüísticos, clases de idiomas para profesores y alumnos, material de la asignatura en el segundo idioma, etc.

\section{Conclusiones}

La necesidad de conocer diferentes idiomas es una realidad emergente en nuestra sociedad (Comisión Europea, 2006; Consejo de Europa, 2009). Cada día, la escuela y la universidad se enfrentan a una realidad más compleja, socialmente construida con procesos de interacción que se desarrollan entre sus miembros y el contexto (Coronel-Llamas, 2007).

En este andamiaje, encontramos que el fomento de planes de plurilingüismo comienza a ser un factor clave para la mejora y la formación en idiomas de nuestro alumnado (Marsh, 1994), ya que este tiene una formación muy básica en idiomas (Caballero-Calavia, 2008; Rubio-Alcalá \& Hermosín-Mojeda, 2010).

Con base en los resultados que hemos obtenido, concluimos que el alumnado del grupo estudiado en su mayoría tiene una actitud abierta al aprendizaje del idioma y considera que el uso de este en el aula universitaria es una oportunidad para mejorarlo. Estos resultados coinciden con otros trabajos realizados en el mismo contexto (Toledo, Rubio-Alcalá \& HermosínMojeda, 2012) y también con los expresados en trabajos como el de Emma Dafouz-Milne, Begoña NúñezPerucha, Carmen Sancho y Diana Foran (2007), en el que los estudiantes resaltan su interés por mejorar en idiomas y puntualizan que la docencia universitaria en inglés consigue mejorar su nivel. Así, los estudiantes mejoran su actitud hacia el idioma, y su propio aprendizaje en el aula hace que en muchos casos desaparezca la sensación de ridículo o inferioridad por el bajo nivel (Casal \& Moore, 2009).

De acuerdo con Sonia Casal y Pat Moore (2009), María Soledad Hoyos-Pérez (2011), David Lasagabaster (2007), María Teresa Navés y Carmen Muñoz (1999), entre otros, nuestro estudio constata también, según los estudiantes, que la formación del profesorado en idiomas debe ser más alta. Así, concluimos que uno de los límites de la profesora que hemos estudiado es su nivel en el idioma y consideramos que debe ser un aspecto a mejorar para dar una enseñanza de calidad en lengua inglesa. Este aspecto puede provocar en la profesora situaciones de estrés e inseguridad en el aula. Problema identificado también en otras investigaciones como la de Robert Wilkinson (2004).

Los resultados de este estudio nos llevan a concluir que la metodología CLIL y las metodologías activas, junto con las estrategias didácticas y recursos elaborados, son un camino para el desarrollo de la lengua y para la adquisición del aprendizaje (Coyle, 2013; De Miguel-Díaz, 2006). Hemos Ilegado a dilucidar que el alumnado está contento con la metodología utilizada por la profesora considerando que esta metodología los ha motivado y autoexigido en el ámbito de la lengua. Así, llegamos a la conclusión de que el uso de una segunda lengua en el aula lleva al profesorado a utilizar estrategias metodológicas que fomenten la interacción y el uso de esta segunda lengua, lo cual se convierte en una ventaja para asimilar ese idioma (Lasagabaster, 2007).

Concluimos que los aspectos que el alumnado resalta de la docente son su implicación en la materia y su "forma de dar clase" centrada en el alumno y en los intereses del mismo (García-Prieto, 2014), lo que define el perfil docente de la profesora y lo asemeja a un modelo investigador en el que ambos agentes (profesor y alumno) son investigadores, y le da importancia a la unión de la teoría y la práctica para la construcción del conocimiento y para la mejora de la segunda lengua (Woods, 1996). En este sentido, hemos avanzado en la necesidad que apunta Emma Dafouz-Milne (2011) de mejorar la metodología utilizada por el profesorado en el aula, para que se consiga maximizar los logros del alumnado en su competencia lingüística.

Las prácticas bilingües, junto a las metodologías con las que se buscaba la interacción entre alumnos y entre estos y la docente en el grupo estudiado, han contribuido a la obtención de resultados muy satisfactorios en esas materias y han provocado la motivación del alumnado hacia el aprendizaje del segundo idioma consiguiendo que muchos de ellos lo utilicen en todas las tareas y actividades desarrolladas a lo largo de la asignatura.

Una de las propuestas del alumnado es la mejora del nivel del idioma, no siendo este un impedimento para entender la asignatura, pero sí un pequeño obstáculo en la comprensión total por parte del alumnado. El uso de la segunda lengua en el aula es un factor más positivo que negativo según los estudiantes y la profesora participantes en esta investigación, ya que permite mejorar el idioma, conocer vocabulario específico y explorar la temática dada en otros países.

En el desarrollo de la investigación, hemos identificado limitaciones que se derivan, por una parte, de las dificultades idiomáticas, que aunque contaban con recursos humanos como un lector, no son suficientes a la luz de la experiencia; $y$, por otra, del gran volumen de información que ha generado, lo que en ocasiones complica en exceso los análisis pertinentes y la elaboración del informe final. Unido a lo anterior, aunque nos consta que algunos alumnos se han presentado a exámenes de certificación de niveles superiores de la segunda lengua (C1 y C2), no tenemos constancia "certificada" del avance que esta experiencia ha 
supuesto para todos ellos, tras cuatro años de trabajo. Para futuros trabajos, deberemos tenerlo en cuenta, para conocer el grado de efectividad, ya que como se pone de manifiesto en los trabajos de Víctor Manuel PavónVázquez (2009) o Carmen Pérez-Vidal y Nancy Campanale-Grilloni (2005), no siempre estos programas consiguen una mejora en el nivel idiomático del alumnado.

Ello nos lleva a prever posibles líneas futuras de trabajo en la investigación relacionada con la enseñanza plurilingüe, empleando CLIL y el uso de metodologías activas para la mejora del aprendizaje del estudiante, como la influencia del uso del inglés en el rendimiento académico de los alumnos, haciendo comparativas con grupos experimentales (con y sin aplicación del enfoque CLIL); las actitudes del alumnado ante la enseñanza plurilingüe; propuestas de mejora para el uso de la metodología CLIL; el uso de la metodología CLIL en la enseñanza plurilingüe y otras. En concreto, a partir de esta investigación, podemos señalar tres cuestiones para desarrollar en próximas investigaciones. Sería interesante profundizar en el uso de la metodología CLIL: a) como una herramienta para la mejora de la relación profesor-alumno, b) analizar el impacto del uso del segundo idioma en el trabajo del docente maestro, o c) para mejorar el aprendizaje de un segundo idioma.

Esta investigación ha ayudado a la docente a mejorar sus prácticas y ha promovido y motivado en ella el afán de superación en su docencia. Además, ha supuesto un nuevo replanteamiento de su nivel de idioma y le ha provocado un mayor interés en mejorarlo. Esta mejora en la autovaloración positiva ha sido identificada en los trabajos de Christiane DaltonPuffer (2005), por ejemplo.

En el caso de los alumnos, valoran muy positivamente la experiencia, que potencia su motivación por el uso de la segunda lengua, adquirir nuevas competencias y contenidos tanto específicos de las materias como generales de la titulación y de la segunda lengua. Consideramos por tanto que el plurilingüismo es una herramienta útil para la mejora de los idiomas y las metodologías activas favorecen el desarrollo de clases plurilingües, ya que suponen un sustento para el alumnado y un enriquecimiento de la enseñanza.

Creemos que nuestro alumnado ha crecido profesionalmente, gracias también a las metodologías activas empleadas. Ellos han sido capaces, como dice Antonio Bolívar (2005), en sus producciones tanto orales como escritas, de transformar nuestra enseñanza en representaciones didácticas que han aplicado ya en su desempeño docente durante las prácticas. Para nosotros, han llegado a interiorizar el uso cotidiano de la segunda lengua en el aula, y el enfoque global que deben alcanzar en sus programaciones pensando en sus futuros alumnos de primaria, y en la posibilidad y aspiraciones que deben poseer respecto a su papel en la transformación de la escuela.

\section{Sobre los autores}

Inmaculada Gómez-Hurtado es doctora en psicopedagogía. Profesora en el área de didáctica de las Ciencias Sociales de la Facultad de Ciencias de la Educación de la Universidad de Huelva. Imparte docencia en los grados de educación infantil y de educación primaria así como en el máster de educación oficial en educación especial de la Universidad de Huelva. Sus principales líneas de investigación se desarrollan en el campo de la atención a la diversidad, la didáctica de las Ciencias Sociales en la educación infantil y primaria, el estudio de la organización y gestión de centros educativos y el liderazgo educativo. Participa en diferentes 
proyectos de investigación de convocatorias competitivas y sus publicaciones versan sobre estas líneas de investigación. Es miembro de la Red de Investigación sobre Liderazgo para la Mejora Educativa, RILME.

María José Carrasco-Macías es doctora en psicopedagogía. Trabaja como profesora titular del Departamento de Educación de la Universidad de Huelva. Imparte docencia en los grados de maestro y de educación social así como en los másteres de educación intercultural y en el máster de educación especial de la Universidad de Huelva. Sus líneas principales de investigación son el estudio de la organización y gestión de centros educativos, educación intercultural y estudios de género. Es coautora de un manual de organización del centro escolar y autora de un libro sobre dirección escolar desde la perspectiva de género, además de otras publicaciones en capítulos de libros y revistas indexadas.

Pilar García-Rodríguez es profesora del Departamento de Educación, área de didáctica y organización escolar en la Facultad de Ciencias de la Educación de la Universidad de Huelva. Ha trabajado como profesora en la Universidad desde 1998. Trabajó dos años como maestra. Consiguió el grado de doctora en julio de 2002, con un trabajo centrado en la evaluación de las modalidades de formación permanente del profesorado universitario. Sus líneas de investigación han ido diversificándose y en la actualidad están relacionadas con acceso a la universidad, evaluación institucional, dirección escolar y abandono escolar prematuro. Durante tres años, ha sido directora de acceso de la universidad y en la actualidad es directora de calidad.

\section{Referencias}

Alcón-Soler, E. (2011). La universidad multilingüe. Revista de Docencia Universitaria, REDU, 9 (3), 119-127. Recuperado de http://red-u.net/redu/ files/journals/1/articles/304/public/304-630-1-PB.pdf

Álvarez-Gayou Jurgenson, J. L. (2003). Cómo hacer investigación cualitativa: fundamentos y metodología. Barcelona: Paidós. Recuperado de http://www.derechoshumanos.unlp.edu.ar/assets/files/documentos/ como-hacer-investigacion-cualitativa.pdf

Andersson, I.; Kagwesage, A. M. \& Rusanganwa, J. (2013). Negotiating Meaning in Multilingual Group Work: A Case Study of Higher Education in Rwanda. International Journal of Bilingual Education and Bilingualism, 16 (4), 436-450. Recuperado de https://www.researchgate.net/ publication/241712793_Negotiating_meaning_in_multilingual_group_ work_A_case_study_of_higher_education_in_Rwanda

Barrios-Espinosa, M. E. (2012). Módulo 7: Aprendizaje Integrado de Contenido y Lengua Extranjera (AICLE). Aula Virtual Formación del Profesorado, Orientaciones para el desarrollo de una secuencia AICLE en CCSS. Recuperado de: https://ieselpalobilingual.wikispaces.com/file/ view/AICLE Elvira Barrios-course-online.pdf

Belvis-Pons, E., Pineda-Herrero, P. \& Moreno-Andrés, M. V. (2007). La participación de los estudiantes universitarios en programas de movilidad: factores y motivos que la determinan. Revista Iberoamericana de Educación, 42, 5-25. Recuperado de http://rieoei.org/ deloslectores/1532Pineda.pdf

Biggs, J. \& Tang, C. (2003). Teaching for Quality Learning at University. Buckinghamshire: Society for Research into Higher Education and Open University Press. Recuperado de http://www.umweltbildungnoe.at/upload/files/OEKOLOG\%202014/2_49657968-Teaching-forQuality-Learning-at-University.pdf

Bolívar, A. (2005). Conocimiento didáctico del contenido y didácticas específicas. Profesorado, Revista de Currículum y Formación del 
Profesorado, 9 (2), 1-39. Recuperado de http:// www.ugr.es/ recfpro/rev92ART6.pdf

Caballero-Calavia, M. G. (2008). Las competencias bilingües como objetivo. Experiencias docentes. Cauce, Revista Internacional de Filología y su Didáctica, 31, 89-101. Recuperado de http:// cvc.cervantes.es/literatura/cauce/pdf/cauce31/ cauce_31_007.pdf

Casal, S. \& Moore, P. (2009). The Andalusian Bilingual Sections Scheme: Evaluation and Consultancy. International CLIL Research Journal, 1/2, 36-46. Recuperado de http://www.icrj.eu/12/article4. html

Ceballos-Herrera, F. A. (2009). El informe de investigación con estudio de casos. magis, Revista Internacional de Investigación en Educación, 1 (2), 413-423. Recuperado de http:// revistas.javeriana.edu.co/index.php/MAGIS/ article/download/3394/2583

Coleman, J. A. (2006). English-Medium Teaching in European Higher Education. Language Teaching, 39, 1-14.

Comisión de las Comunidades Europeas (2003). Promover el aprendizaje de idiomas y la diversidad lingüística: un plan de acción 2004-2006. Comunicación de la Comisión al Consejo, al Parlamento Europeo, al Comité Económico y Social y al Comité de las Regiones, $\operatorname{COM}(2003)$ 449 final. Bruselas. Recuperado de http:// eurlex.europa.eu/LexUriServ/LexUriServ. do? uri=COM:2003:0449:FIN:ES:PDF

Comisión Europea (1998). Recommandation (98) 6 concernant les langues vivantes. Recuperado de https://rm.coe.int/CoERMPublicCommonSearch Services/DisplayDCTMContent?documentld=09 $000016804 f d a 7 c$

Comisión Europea (2006). Los europeos y sus lenguas. Eurobarómetro Especial 243. Recuperado de http://ec.europa.eu/spain/pdf/eurobar_ lenguas_es.pdf

Consejo de Europa (2002). Marco común europeo de referencia para las lenguas: aprendizaje, enseñanza, evaluación. Instituto Cervantes (trad.). Madrid: Ministerio de Educación, Cultura y Deporte (Subdirección General de Cooperación Internacional, para la edición impresa en español), Secretaría General Técnica del MECD-Subdirección General de Información y Publicaciones, y Grupo ANAYA. Recuperado de http://cvc. cervantes.es/ensenanza/biblioteca_ele/marco/ cvc_mer.pdf

Consejo de Europa (2009). Conclusiones del Consejo de 12 de mayo de 2009 sobre un marco estratégico para la cooperación europea en el ámbito de la educación y la formación ("ET 2020").
Diario Oficial, C 119, 28 de mayo de 2009, 0002-0010. Recuperado de http://publications. europa.eu/resource/cellar/f349e9ff-9cb8-4f73b2f6-0a13452d22b4.0007.02/DOC_1

Contreras-González, L.C.; Rodríguez-López, J. M. \& Morales-Gil, F.J. (eds.) (2005). Innovamos juntos en la Universidad. Huelva: Servicio de Publicaciones de la Universidad de Huelva.

Coronel, J. M. (2007). Las culturas organizativas. En María José Carrasco-Macías, José Manuel Coronel-Llamas, María Luisa Fernández-Serrat, Sebastián González-Losada \& Emilia MorenoSánchez (eds.). Organización Escolar. Aspectos básicos para docentes, 189-206. 2ª ed. Granada: Grupo Editorial Universitario.

Cots, J. M.; Lasagabaster, D. \& Garrett, P. (2012). Multilingual Policies and Practices of Universities in Three Bilingual Regions in Europe. International Journal of the Sociology of Language, 216, 7-32.

Coyle, D. (2004). Supporting Students in Content and Language Integrated Contexts: Planning for Effective Classrooms. In John Masih (ed.). Learning through a Foreign Language: Models, Methods and Outcomes, 40-54. Lancaster: Centre for Information on Language Teaching and Research, CILT. Recuperado de http://files.eric. ed.gov/fulltext/ED454735.pdf

Coyle, D. (2007). Content and Language Integrated Learning: towards a Connected Research Agenda for CLIL Pedagogies. International Journal of Bilingual Education and Bilingualism, 10 (5), 543-562.

Coyle, D. (2010). Foreword. En David Lasagabaster \& Yolanda Ruiz de Zarobe (eds.). CLIL in Spain. Implementation, Results and Teacher Training, 7-8. Newcastle: Cambridge Scholars Publishing.

Coyle, D. (2013). Listening to Learners: An Investigation into 'Successful Learning' across CLIL Contexts. International Journal of Bilingual Education and Bilingualism, 16 (13), 244-266. Las iniciales son J. M. de Juan Manuel, NO F

Dafouz-Milne, E. (2011). English as the Medium of Instruction in Spanish Contexts: A Look at Teacher Discourses. En Yolanda Ruiz de Zarobe, Juan Manuel Sierra \& Francisco Gallardo del Puerto (eds.). Content and Foreign Language Integrated Learning: Contributions to Multilingualism in European Contexts, 189-209. Berna: Peter Lang, Linguistic Insights: Studies in Language and Communication, Volume 108.

Dafouz-Milne, E. \& Guerrini, M. (eds.) (2009). CLIL across Educational Levels: Experiences from Primary, Secondary and Tertiary Contexts. Madrid: Richmond-Santillana. 
Dafouz-Milne, E. \& Llinares-García, A. (2008). The Role of Repetition in CLIL Teacher Discourse: A Comparative Study at Secondary and Tertiary Levels. International CLIL Research Journal, 1, 50-59. Recuperado de http://www.icrj.eu/11/article4.html

Dafouz-Milne, E. \& Núñez-Perucha, B. (2009). CLIL in Higher Education: Devising a New Learning Landscape. En Emma Dafouz-Milne Michele C. Guerrini (eds.). CLIL across Educational Levels: Experiences from Primary, Secondary and Tertiary Contexts, 101-112. Madrid: Richmond-Santillana.

Dafouz-Milne, E.; Núñez-Perucha, B.; Sancho, C. \& Foran, D. (2007). Integrating CLIL at the Tertiary Level: Teachers' and Students' Reactions. En Dieter Wolff \& David Marsh (eds.). Diverse Contexts Converging Goals. Content and Language Integrated Learning in Europe, 4, 91-102. Frankfurt: Peter Lang. Recuperado de https://www.academia. edu/1037953/Integrating_CLIL_at_the_tertiary_ level_teachers_and_students_reactions

Dalton-Puffer, C. (2005). Negotiating Interpersonal Meanings in Naturalistic Classroom Discourse: Directives in Content-and-Language-Integrated Classrooms. Journal of Pragmatics, 37, 1275-1293.

Dalton-Puffer, C. (2011). Content and Language Integrated Learning: from Practice to Principles. Annual Review of Applied Linguistics, 31, 182-204.

Dalton-Puffer, C.; Nikula, T. \& Smit, U. (eds.) (2010). Language Use and Language Learning in CLIL Classrooms. Amsterdam: Benjamins.

Donmoyer, R. \& Galloway, F. (2010). Reconsidering the Utility of Case Study Designs for Researching School Reform in a Neo-Scientific Era: Insights from a Multiyear, Mixed-Methods Study. Educational Administration Quarterly, 46 (1), 3-30.

Elliott, J. \& Lukeš, D. (2008). Epistemology as Ethics in Research and Policy: The Use of Case Studies. Journal of Philosophy of Education, 42 (1), 88119. Recuperado de https://www.researchgate. net/publication/229687611_Epistemology_As_ Ethics_In_Research_And_Policy_The_Use_of_ Case_Studies

Fernández-March, A. (2006). Metodologías activas para la formación de competencias. Educatio siglo XXI, 24, 35-56. Recuperado de http:// www.unizar.es/ice/images/stories/materiales/ curso35_2009/Metodologiasactivas.pdf

García-Prieto, F. J. (2014). El proceso de enseñar a aprender. Modelos didácticos. Inmaculada Gómez-Hurtado \& Francisco Javier García-Prieto (coords.). Manual de didáctica: Aprender a enseñar, 25-44. Madrid: Pirámide.

García-Valcárcel Muñoz-Repiso, A. (2001). Didáctica universitaria. Madrid: La Muralla.
Goicoechea-Tabar, M. J.; Ballarín-Castán, A. \& FontalReglero, R. (2007). Una aproximación a la enseñanza de lenguas en la Unión Europea. Perspectiva CEP 13, 7-43. Recuperado de http://www. juntadeandalucia.es/educacion/webportal/ abaco-portlet/content/c63fdab9-a13d4970-b1b5-3937acb430bd

Hoyos-Pérez, M. S. (2011). El desafío de los programas plurilingües en España. Cuadernos Comillas, 2, 37-50. Recuperado de http://www.fundacion comillas.es/cuadernos-comillas/cuadernos/lexico/pdf/cuaderno.pdf

Johnson, B. \& Christensen, L. (2004). Educational Research. Quantitative, Qualitative, and Mixed Approaches. $2^{\text {nd }}$ ed. Boston: Pearson Education.

Junta de Andalucía (2013). Plan de Fomento del Plurilingüismo.

Lam, A. (2001). Bilingualism. En Ronald Carter \& David Nunan (Eds.) The Cambridge Guide to Teaching English to Speakers of Other Languages, 93-99. Cambridge: Cambridge University Press.

Lasagabaster, D. (2007). Language Use and Language Attitudes in the Basque Country. En David Lasagabaster \& Ángel Huguet-Canalís (eds.) Multilingualism in European Bilingual Contexts. Language Use and Attitudes, 65-89. Clevedon: Multilingual Matters.

Lasagabaster, D. (2012). El papel del inglés en el fomento del multilingüismo en la Universidad. Estudios de Lingüística Inglesa Aplicada (ELIA), 12, 13-44. Recuperado de http://laslab.org/upload/el papel_del_ingl\%C3\%A9s_en_el_fomento_del_ multiling\%C3\%BCismo_en_la_universidad.pdf

Lorenzo, F. (2002). Stages in Content-Based Instruction Course Development in English Teaching at Tertiary Level. En Antonio Bueno-Glez, Gabriel Tejada-Molina \& Gloria Luque-Agulló (eds.). Las lenguas en un mundo global. XX Congreso Nacional de la Asociación Española de Lingüística Aplicada, AESLA, 179-191. Jaén: Universidad de Jaén.

Lorenzo, F. (2008). Instructional Discourse in Bilingual Settings. An Empirical Study of Linguistic Adjustments in Content and Language Integrated Learning. Language Learning Journal, 36 (1), 21-33.

Marsh, D. (1994). Bilingual Education \& Content and Language Integrated Learning. International Association for Cross-Cultural Communication, Language Teaching in the Member States of the European Union (Lingua). Paris: University of Sorbonne.

Marsh, D. (2008). Language Awareness and CLIL. In Jasone Cenoz \& Nancy Hornberger (eds.). 
Encyclopedia of Language and Education, Knowledge about Language, 6, 233-246. New York: Springer.

Medina-Moya, J. L. (2014). El proceso de comprensión en el análisis de datos cualitativos en educación. magis, Revista Internacional de Investigación en Educación, 7 (14), 39-54. Recuperado de http://revistas. javeriana.edu.co/index.php/MAGIS/article/view/11855/pdf_1

Miguel-Díaz, M. de (coord.) (2006). Metodologías de enseñanza y aprendizaje para el desarrollo de competencias: orientaciones para el profesorado universitario ante el Espacio Europeo de Educación Superior. Madrid: Alianza.

Navés, M. T. \& Muñoz, C. (1999). CLIL Experiences in Spain. Implementation of CLIL in Spain. En David Marsh \& Gisella Langé (eds.). Implementing Content and Language Integrated Learning, 145-158. Jyäskylä, Finland: UniCOM, University of Jyäskylä and TIE-CLIL. Recuperado de www.ub.edu/filoan/addendumen.html

Pavón-Vázquez, V. M. (2009). La introducción de un programa de enseñanza integrada de lengua y contenidos en la educación superior: claves para impartir asignaturas a través de una segunda lengua. En Víctor Manuel Pavón-Vázquez \& Francisco Javier Ávila-López (eds.). Aplicaciones didácticas para la enseñanza integrada de lengua y contenidos (AICLE/CLIL/ÉMILE), 29-53. Sevilla: Consejería de Educación, Universidad de Córdoba, Asociación de Profesores de Inglés de Córdoba, CETA.

Pavón-Vázquez, V. \& Rubio-Alcalá, F. D. (2010). Teachers' Concerns and Uncertainties about the Introduction of CLIL Programmes. Porta Linguarum, 14, 45-58. Recuperado de https://dialnet.unirioja.es/descarga/ articulo/3253054.pdf

Pérez-Vidal, C. \& Campanale-Grilloni, N. (eds.) (2005). Content and Language Integrated Learning (CLIL) in Europe. Barcelona: Printulibro Intergrup.

Ponsa, P.; Amante, B.; Román, J. A.; Oliver, S.; Díaz, M. \& Vives-Gràcia, J. (2009). Higher Education Challenges: Introduction of Active Methodologies in Engineering Curricula. International Journal of Engineering Education, 25 (4), 799-813. Recuperado de http://eprints. rclis.org/15211/1/Introduction\%20of\%20Active\%20Methodologies \%20in\%20Engineering.pdf

Rodríguez-Torres, J. (2011). Los rincones de trabajo en el desarrollo de competencias básicas. Revista Docencia e Investigación, 21, 105-130. Recuperado de https://www.uclm.es/varios/revistas/docenciaeinves tigacion/pdf/numero11/06.pdf

Rubio-Alcalá, F. \& Hermosín-Mojeda, M. J. (2010). Implantación de un programa de plurilingüismo en el espacio europeo de educación superior. XXI, Revista de Educación, 12, 107-124. Recuperado de http:// www.tesol-spain.org/uploaded_files/files/Fernando-Rubio-2.pdf

Rué, J. (2007). Enseñar en la universidad. Madrid: Narcea.

Sánchez-Moreno, M. (2007). Cómo enseñar en las aulas a través del estudio de casos. Zaragoza: Instituto de Ciencias de la Educación, ICE, Universidad de Zaragoza. Recuperado de http://www.unizar.es/ice/ images/stories/calidad/Casos.pdf

Stake, R. E. (2010). Qualitative Research: Studying How Things Work. New York: The Guilford Press.

Suárez-Castiñeira, M. L. (2005). Aprendizaje Integrado de Contenidos y Lengua Extranjera (AICLE): una de las claves para la convergencia europea. En II Jornadas Internacionales de Innovación Universitaria: El reto de la Convergencia Europea. Deusto: Universidad de Deusto. 
Suárez-Castiñeira, M. L. (2006). Implantación de AICLE [Aprendizaje Integrado de Contenidos y Lenguas Extranjeras] en Europa y sus implicaciones para la formación del profesorado. Ponencia presentada en Xornadas sobre ensino bilingüe. Seccións Europeas e Aulas Bilingües. Santiago de Compostela: Consellería de Cultura, Educación e Ordenación Universitaria, Xunta de Galicia.

Toledo, I.; Rubio-Alcalá, F. \& Hermosín-Mojeda, M. J. (2012). Creencias, rendimiento académico y actitudes de alumnos universitarios principiantes en un programa plurilingüe. Porta Linguarum, 18, 213-229. Recuperado de http://www.ugr.es/ portalin/articulos/PL_numero18/ 13\%20\%20lsabelle\%20Toledo.pdf

Ubieto-Artur, M. I. (coord.); Domingo del Valle, M.; García-Marco, F. J. \& Ubieto-Artur, A. P. (2008). Practicar con la teoría: metodologías activas en información y documentación en el marco del Espacio Europeo de Educación Superior. Zaragoza: Prensas Universitarias de Zaragoza.

UNESCO (2003). La educación en un mundo plurilingüe. París: Organización de las Naciones Unidas para la Educación, la Ciencia y la Cultura, UNESCO. Recuperado de http://unesdoc.unesco.org/ images/0012/001297/129728s.pdf

Wiersma, W. \& Jurs, S. G. (2000). Research Methods in Education: An Introduction. $7^{\text {th }}$ ed. Boston: Allyn and Bacon.

Wilkinson, R. (ed.) (2004). Integrating Content and Language. Meeting the Challenge of a Multilingual Higher Education. Maastricht: Universitaire Pers Maastricht.

Woods, P. (1996). Researching the Art of Teaching, Ethnography for Educational Use. London, New York: Routledge.

Yin, R. K. (2014). Case Study Research. Design and Methods. London: Sage Publications.

Zabalza-Beraza, M. Á. (2002). La enseñanza universitaria. El escenario y sus protagonistas. Madrid: Narcea.

Zabalza-Beraza, M. Á. \& Zabalza-Cerdeiriña, M. A. (2010). Planificación de la docencia en la Universidad: elaboración de las guías docentes de las materias. Madrid: Narcea. 